\title{
A Literature Review of New Types of Scientific Research Institutions*
}

\author{
Quanlu Lin \\ Lanzhou University of Technology \\ Lanzhou, China 730000
}

\author{
Bingyi Song \\ Lanzhou University of Technology \\ Lanzhou, China 730000
}

\begin{abstract}
Featuring diversified sources of investment, marketization of resource allocation, enterprise management mechanism, demand orientation of research and development, internationalization of talent team and collaborative innovation of enterprises, academia, and research institutes, etc., new types of scientific research institutions are scientific research organizations that take knowledge exploration and scientific and technological innovation as their main activities, devote themselves to the industrialization development of scientific and technological achievements, and lead the construction of regional innovation system. This paper reviews and sorts out the background, definition, characteristics, classification, functional positioning, operation mechanism, operation effect and evaluation of new types of scientific research institutions, so as to provide beneficial reference for the development and improvement of them and enhancing their service functions.
\end{abstract}

Keywords-new types of scientific research institutions; comb; review

\section{INTRODUCTION}

Innovation-driven growth plays a vital role in China's economic and social development. However, the phenomenon of weak innovation capacity at the source of industry, difficulty in breakthrough of core technologies in emerging industries, insufficient innovation vitality of scientific research institutions and low conversion rate of scientific and technological achievements still exist. As an important carrier of innovation-driven development, new types of scientific research institutions (hereinafter also referred to as "new types of Scientific research institutions") break the limitations of traditional research organizations in coordination mechanism, operation mode, research and development mode, functional positioning and openness, and realize the close integration of science and technology with economy. Such new type of scientific research organization is an important part of national and regional innovation system. In recent years, it has been developing vigorously in the southeast coastal areas such as Guangdong, Jiangsu and Zhejiang, attracting scholars to study it from different perspectives. In 2019, the No. 1 document of the party

*Fund Project: This paper is funded by the National Social Science Foundation: "Research on Constructing New Agricultural Management System and Innovative Agricultural Management Mode in Contiguous Poverty-stricken Areas in Northwest China" (Project No.: 14XJY014).

CLC No.: G311; Document code: A organization of the Ministry of Science and Technology stressed the importance of further promoting the role of science and technology innovation carriers in the transformation of scientific and technological achievements, incubation of scientific and technological entrepreneurship and cultivation of talents for entrepreneurship and innovation, which pointed out the direction for the rapid development of new types of Scientific research institutions.

\section{BACKGROUND OF NEW TYPES OF SCIENTIFIC RESEARCH INSTITUTIONS}

The global economy is entering a period of deep adjustment, and science and technology are increasingly becoming the main force to promote economic and social development. The intensification of international competition constantly pushes technological innovation activities to break through the boundaries of regions and organizations [1]. In order to gain advantages in the market competition, enterprises continue to integrate resources and build good cooperation channels. They build new types of scientific research institutions with universities and research institutes under the guidance of the government.

External causes for the emergence of new types of scientific research institutions include economic factors, market factors, policy factors and technical factors [2]. At the same time, the phenomenon of low marketization level of scientific and technological achievements and great difficulty in technology popularization still exist, and the government needs to provide policy support, project support and financial support to promote the reform of science and technology system. New types of Scientific research institutions seek the connection between the supply of scientific and technological resources and market demand with the help of the government's participation of the "tangible hand" [3].

Their internal motivation includes organization factor, resource factor and collaboration factor, etc. The operation and development of traditional scientific research institutions are out of touch with the market and industry, so it is difficult to give full play to their application value. In order to obtain the synergetic effect of "1+1 > 2", participants actively explore the way of commercialization of scientific and technological achievements. With giving full play to the good market operation mechanism as the starting point, they establish new types of scientific research institutions based on the premise of resource sharing and making their 
respective advantages. Through mutual learning and cooperation, the effect of continuous optimization of resource allocation, continuous improvement of technological innovation ability and continuous reduction of $\mathrm{R} \& \mathrm{D}$ cost can be rapidly achieved, so as to achieve the winwin goal [2].

\section{DEFINITION AND CHARACTERISTICS OF NEW TyPES OF SCIENTIFIC RESEARCH INSTITUTIONS}

\section{A. Definition of New Types of Scientific Research Institutions}

Chen Baoming, [4] the earliest scholar who studied such scientific research organizations with "new types of scientific research institutions", he proposed in 2013, a new type of research and development institution was based on knowledge exploration and technological innovation, carrying out scientific and technological research and development, achievement transformation and other activities to promote institutional innovation and service innovation, cultivate innovative talents and create a good innovation ecological environment. From the perspective of individual cases, Zeng Guoping, Lin Fei, [5] summarized that a new type of research and development institution is an innovative and entrepreneurial $R \& D$ organization with the organizational concept of "scientific discovery, technological invention and industrial development", the development mode of "science and technology", "industry", "education" and "capital", and the operation mode of "state-owned new system" or "private and public assistance". From the perspective of achievement transformation, Chen Hongxi, Jiang Chun et al. [6] emphasized that the new types of scientific research institutions was a kind of international mixed ownership organization with strategic emerging industries as its functional orientation, which relied on institutions of higher learning and research institutes, and took modern enterprise operation and management as the criterion. They hold that it was a mixed type featuring "being led by technology and backed by science" and an upward spiral taking "technical science being the inherent nature and the incubation and development of technology enterprises being the external manifestation" as the core.

\section{B. Characteristics of New Types of Scientific Research Institutions}

From traditional scientific research organizations to new types of scientific research institutions, the "newness" of new types of scientific research institutions is mainly reflected in the following five aspects:

1) New synergy mechanism: New types of scientific research institutions embody the concept of collaborative innovation in their development. Different from the single investment body of traditional scientific research organizations, the new types scientific research institutions, based on the vision of multi-party cooperation, cooperate with innovation bodies such as universities, scientific research institutes, enterprises, governments and intermediaries to form scientific research synergy and promote the exchange, integration and flow of resources among the whole organization, so as to improve the hi-tech innovation capacity. [7][8]

2) New operation mode: New types of scientific research institutions adopt modern enterprise operation and management mechanism, incentive mechanism and employment mechanism to meet the realistic requirements of the industry with market demand. In terms of internal management, they adopt the mode of "non-profit organization management" to implement the separation of management and investment, separation of execution and decision-making, and independent accounting and other systems. [9]

3) New research and development mode:The new types of scientific research institutions carry out research and development activities around the industrialization target, breaking through the limitation of traditional research organizations focusing on a certain link, building a bridge between the scientific and industrial development, and forming a set of whole industrial chain docking system from source innovation to industrial transformation [10].

4) Clear function positioning: The new types of scientific research institutions with market-oriented operation are the combination of the main innovation bodies (universities, governments and enterprises) to promote the collaberation of scientific and technological innovation foundation (talents, technology, capital and equipment), and an important platform to accelerate the integration of industry, education and research, integrate innovative talents and promote the transformation of achievements [11]. With strong government orientation, the new types of scientific research institutions aim at the forefront of science, technology and industrial development, devote themselves to creating industrial value, become industry drivers and directly serve local economic construction at the beginning of their establishment [10]

5) Strong openness: The open characteristics of the global system of new types of scientific research institutions are mainly reflected in the selection and appointment of talents [10]. In order to break the "in-system" restriction and develop in the competition, the contract system, the dynamic evaluation system and the last-place elimination system are widely adopted. Modes like innovation and entrepreneurship encoureagement, judge people not by age or academic degree but by ability and so on have attracted more excellent human resources. [12] [13]

\section{ClassifiCATION OF NEW TYPES OF SCIENTIFIC RESEARCH INSTITUTIONS}

The establishment mode of the new types of scientific research institutions is mainly divided into two categories: oriented-construction type and self-construction type.

The oriented-construction type can be divided into five types: government-oriented, university-oriented, scientific 
research institutions-oriented, enterprise-oriented, social organizations or individuals-oriented [14].

The new government-oriented scientific research institutions are committed to providing non-profit services, focusing on supporting the development of generic technologies in the industry, as well as supporting the development of emerging technologies and industrial transformation and upgrading. This model is mainly adopted in the early stage of cultivation of various types of institutions including public institutions, enterprises and private non-enterprises. Typical institutions include National Institute of Biological Sciences, Beijing, Shanghai Industrial Technology Institute, etc.

The new university-oriented scientific research institutions are based on high-quality academic resources and focus on supporting the diffusion of key technology innovation in the industry. This mode is mostly adopted in the middle period of construction and is mainly used by public institutions. The typical institutions are Research Institute of Tsinghua University in Shenzhen, Zhongyuan Advanced Technology Research Institute of Tianjin University and so on.

The new scientific research institutions-oriented scientific research institutions are partly reformed from traditional research institutes, promoting the localization development of industry generic technologies and key technologies with the focus on upstream scientific research. This mode is mostly adopted in the middle period of construction, mostly in public institutions. Typical institutions include (Shenzhen Institutes of Advanced Technology, Chinese Academy of Sciences and Guangzhou Institute of Building Science Co., Ltd. and so on.

The new enterprise-oriented scientific research institutions gain benefits by serving enterprise technological innovation, absorbing and implementing integrated innovation. This mode is mostly adopted under the condition of relatively perfect construction environment. Most of them are enterprises and private non-enterprises. The new enterprise-oriented scientific research institutions will become the focus in later development. Typical institutions include Media Refrigeration Research Institute, Byd Central Research Institute and so on.

Most of the new social organizations or individualsoriented scientific research institutions led by social organizations or individuals are funded and established by foundations to provide professional scientific research services, which generally reflect the common innovation needs of an industry or focus on a specific industry segment. Most of them are private non-enterprises and public institutions, which will become research intermediaries in the future. Typical institutions include Industrial Technology Research Institute of Taiwan, R.O.C, Zhanjiang Shenglang Marine Fishing Research Institute, etc.

The modes of self-construction are mainly social capital (including state-owned enterprises and private enterprises) self-construction and government self-construction.
The social capital self-construction type are mainly invested and established by state-owned enterprises and private entrepreneurs, which is generally a manifestation of the independence and specialization of $R \& D$ departments of large enterprises. At present, social capital is the main force in the construction of new types of scientific research institutions, such as TCL Industrial Research Institute. [15]

Government self-construction type refers to the scientific research institutions independently built by government departments to improve the public technology level of local industries according to the needs of local industrialization development. Typical institutions include Guangdong Institute of Fuyun Stone and so on. [16]

\section{POSITIONING AND FUNCTIONS OF NEW TyPES OF SCIENTIFIC RESEARCH INSTITUTIONS}

The main obstacle to the sustainable development of traditional scientific research institutions is the vague function positioning, which leads to unclear development goals and makes it difficult to resist external interference. Therefore, accurate positioning is the primary link for new types of scientific research institutions to play a role, realize functional value and win the market [17]. Micheal Fritsch [18] et al. emphasized public research institutions, as important participants in the regional innovation system, will become an important policy tool to stimulate regional development. Zhang Yulei, Li Runyi et al. [19] sorted out the role and functional positioning of the new types of scientific research institutions from the perspective of innovation ecosystem, emphasizing new types of scientific research institutions can promote the overall evolution of innovation ecosystem.

Focusing on the new university-oriented scientific research institutions, universities dominant Zhou Li [20] and $\mathrm{H}$ Etzkowitz [21] emphasized as a natural incubator, this university-oriented type has achieved the transformation from traditional institutions to scientific research management, scientific research teaching, scientific research production, scientific research entrepreneurship, scientific financing institution and it has the function of providing support for potential innovators, building bridges between knowledge and business, and creating a favorable environment for cross-disciplinary development. According to the analysis of Yang Minghai et al. [22], the Tianjin University Office of Science and Technology not only undertakes the basic scientific research function of colleges and universities, but also provides services such as talent training and course training, and connects with the market, providing services such as public testing, scientific and technological innovation and achievement transformation.

In view of the new enterprise-oriented scientific research institutions, Zhao Jiandong and Dai Qingyun [15] believe that this type has gradually become the pillar of applied research, and obtain powerful scientific and technological advantages through subversive technological innovation. Based on the Pasteur quadrant, $\mathrm{Wu}$ Wei and Yin $\mathrm{Lu}$ [9] conducted functional analysis on pre-competition technical research institutions, technical service research institutions, 
entrepreneurial incubation research institutions and public service research institutions.

As for the new government-oriented scientific research institutions, Lin Zhijian [23] and Tan Li [14] et al. emphasized that this type provides industry technology integration as well as generic and key technology research services. This type of new scientific research institutions reflects that the generic key technologies within the industry have the characteristics of "public property". Ding Minglei et al. [24] analyzed the functional positioning of five new federally funded scientific research institutions from the perspective of a case study.

\section{OPERATION MECHANISM OF NEW TYPES OF SCIENTIFIC RESEARCH INSTITUTIONS}

Rational operation mechanism can promote the development of new scientific research institutions. Huang Yuxing and Jin Qinxian [25] conceived the operation system and mechanism of the industrial technology institutes to ensure their sustainable development. Under the leadership of the council, the president responsibility system and the vertical management system are adopted, the development mode of co-construction and cooperation is formed in the R\&D center, and market is expanded in the transfer center. Enterprises, governments, universities and intermediary institutions cooperate to form an innovative ecosystem that is "formed by universities, promoted by the government, participated by enterprises, guided by market and makes key breakthroughs with integration of resources". Xia Taitao et al. [26] took six new types of scientific research institutions in Jiangsu, Guangdong and Shaanxi as examples, and pointed out that the new types of scientific research institutions realized the transformation from research and development innovation to productization and then to marketization, and achieved the industrialization development of results in key areas. Zuo Chaosheng [27] believes that the new types of scientific research institutions break through the disadvantages of independent links in traditional scientific research organizations, create a chain of integrated development of "innovation + industry + capital", and realize the transformation from traditional administrative management mode to modern enterprise management mode. In terms of salary mechanism, they attract high-end talents in China and abroad according to the market-oriented salary level. In terms of employment mechanism, they boldly employ young people with innovative ideas and encourage innovation and entrepreneurship. Zhou Huadong [28] took the industrial technology research institutes in the United States, the United Kingdom and Brazil as examples to describe the development and change of the operation mechanism of Industrial technology research institutes. The development and change are embodied in the transformation from task orientation to compound orientation in terms of function orientation; from research and development services to innovation services in terms of business scope; in the construction mode, from single subject to multi-subject in terms of construction mode; from a single technology field to multi - technology fields comprehensive intersectionn inerms of research and development mode; and from rigid management to flexible management in terms of operating mode. Lin Zhijian [23] put forward that a new type of government-oriented scientific research institution adopts an open cooperative external management mode with government investment as the main, universities, research institutes and enterprises as the support and market demand as the traction, and an internal management mode in which the council makes the decision, industry steering committee provides consultancy services and head of technology department takes charge. Zhou Li [20] described the operation mechanism of new types of scientific research institutions oriented by universities as "four dissimilarities", and the concrete manifestations are as follows. In terms of cooperation, innovation subjects emphasize complementary advantages, concentrate superior resources and transfer high and new technologies to enterprises; in terms of the transformation of achievements, universities will give corresponding resources after screening in order to quickly put scientific and technological achievements into the market, form scale and realize industrialization; in the process of operation, colleges and universities, cope with the changing environment and the threat of competition together with the government, venture capital institutions and other forces. $\mathrm{Li}$ Peizhe, Jian Lirong et al. [29] hold that the operation mechanism of the new enterprise-oriented scientific research institutions is manifested in the following respects: in terms of project selection, $\mathrm{R} \& \mathrm{D}$ investment is made on projects with large market potential, strong competitiveness and low risk; in terms of technology transfer, the channel for knowledge acquisition is opened, and key technologies of industry development are tackled together with innovation subjects to solve technical problems; in terms of profit distribution, a scientific and reasonable distribution mechanism is established to ensure fairness; in terms of incubation mechanism, the advantages of scientific research institutions are utilized to assist small and medium-sized technological innovation enterprises and entrepreneurs to carry out technological research and development and industrial upgrading; and in terms of risk control, special funds are set up for technology research and development. At the same time, expanding the scope of innovation subjects is conducive to common resistance to risks and increase the success rate.

\section{OPERATION EFFECT OF NEW TYPES OF SCIENTIFIC RESEARCH INSTITUTIONS}

The operation effect of the new $R \& D$ institution is quite remarkable, which is manifested in the following three aspects:

\section{A. Driving $R \& D$ Investment of the Whole Society and Enhancing the Clustering of Resources}

Most of the new types of scientific research institutions are jointly invested and established by social forces or joint enterprises of universities and scientific research institutions, but not limited to these - they can also be depend on various types of organizations, such as industrial and technological alliances, venture capital funds, etc. [9]. Through the construction of new types of scientific research 
institutions, the advantages of local industries are closely combined with the advantages of scientific and technological resources of research institutes as well as the advantages of government policies and funds, etc., so as to conduct innovation centering on industrial development and attract capital investment through innovation activities [30]. For example, through the "Shenzhen Metamaterials Industry Alliance", Shenzhen Kuangchi Institute of Technology established an industrial R\&D base, and set up a 2-billionyuan "Industrial Development Fund" to guide independent innovation and entrepreneurship. Relying on the advantages of local economy and industrial development, and based on the scientific research achievements of Kuangchi postdoctoral workstation, the institute focuses on investing in emerging enterprises in the field of metamaterials and supports the upstream and downstream enterprises of the alliance so as to promote the further development of the industry [31].

\section{B. Pooling High-end Talents and Stimulating Innovation}

The distribution mechanism, incentive mechanism, employment mechanism and other personnel training system adopted by the new types of scientific research institutions have the characteristic of developing in competition. At the same time, the rapid transformation of intellectual property rights has mobilized the innovation enthusiasm of R\&D personnel, providing fresh blood for the industry development [32]. For example, Shenzhen Institutes of Advanced Technology, Chinese Academy of Sciences has always taken the construction of "first-class leading talents training base" as one of its core goals and missions. Human resources hired from universities such as the University of Science and Technology of China and the Chinese Academy of Sciences constitute the backbone of the institute. In terms of talent training, more than 1,000 graduate students are trained. In terms of talent introduction, global recruitment is implemented to ensure that more than $60 \%$ of doctoral staff is recruited from overseas [33].

\section{Transforming Scientific and Technological Achievements and Incubating Scientific and Technological Enterprises}

New types of scientific research institutions have achieved rapid development from source innovation and technological innovation to new products. Through cooperation with enterprises and scientific research institutions, they form a group of laboratories and technical centers of a certain scale, laying a foundation for the industry to carry out basic research, applied research and industrial development, and jointly promote the industrialization of results. At the same time, in order to meet the technical requirements of transformation and upgrading of traditional industries, they provide technological services for enterprises in technology development, product design, performance testing and other aspects, incubating a number of high-tech enterprises [34]. For example, Research Center of Tsinghua University in Shenzhen has always put R\&D capacity building in important position and it established a large platform for innovation that integrates scientific and technological research and development, scientific and technological services, transformation of achievements, industrial cultivation and incubation of science and technology. On average, more than 15 scientific and technological achievements are industrialized every year, and the value directly generated by technological innovation exceeds 1 billion yuan [35].

\section{EVALUATION OF THE OPERATION EFFECT OF NEW SCIENTIFIC RESEARCH INSTITUTIONS}

The evaluation and research on the operation effect of new types of scientific research institutions is conducive to the integration of internal resources, the rational allocation of scientific and technological elements, the formation of a strong scientific and technological innovation atmosphere, and better boosting the development of new types of scientific research institutions.

Zhang Yulei, Li Runyi et al. [19] evaluated the development status of new-type scientific research institutions in Guangdong province from four dimensions of R\&D conditions, innovation activities, innovation benefits and talent cultivation. Zhou Ende and Liu Guoxin [14] constructed a theoretical model of the influencing factors of innovation performance from three perspectives, namely, capital and personnel input, government special subsidies and tax relief, and the nature of formation. The construction of evaluation index system of new types of scientific research institutions is shown in "Table I".

TABLE I. System CONSTRUCTION OF EVALUATION INDEX FOR NEW TYPES OF SCIENTIFIC RESEARCh INSTITUTIONS

\begin{tabular}{c|c|c|c}
\hline Name of the system & Means & First-level indicators & Writer \\
\hline $\begin{array}{c}\text { Industrial technology } \\
\text { research institute } \\
\text { performance evaluation } \\
\text { system }\end{array}$ & AHP & $\begin{array}{c}\text { environment, investment, operation, } \\
\text { achievement level, economic benefit, social } \\
\text { benefit, industrial competitiveness }\end{array}$ & $\begin{array}{c}\text { Wang Shouwen et al. } \\
\text { [36] (2014) }\end{array}$ \\
\hline $\begin{array}{c}\text { General performance } \\
\text { indicators of research } \\
\text { institutes of the Hungarian } \\
\text { Academy of Sciences }\end{array}$ & $\begin{array}{c}\text { Questionnaire } \\
\text { survey and the } \\
\text { expert scoring } \\
\text { method }\end{array}$ & $\begin{array}{c}\text { publishing activities, international activities, } \\
\text { education activity, research and development } \\
\text { activities and financing activities }\end{array}$ & P Vinkler [37] (1998) \\
\hline $\begin{array}{c}\text { Operation performance } \\
\text { evaluation system of } \\
\text { industrial technology } \\
\text { research institutes }\end{array}$ & ANP & $\begin{array}{c}\text { behavioral attitude, operating process and } \\
\text { result effectiveness }\end{array}$ & Wang Shouwen et al. \\
[38] (2015)
\end{tabular}




\begin{tabular}{c|c|c|c}
\hline Name of the system & Means & First-level indicators & Writer \\
\hline $\begin{array}{c}\text { Evaluation index system of } \\
\text { collaborative innovation } \\
\text { platform of industrial } \\
\text { technology research institutes }\end{array}$ & $\begin{array}{c}\text { AHP-BP neural } \\
\text { network model }\end{array}$ & $\begin{array}{c}\text { organization cooperation, resources } \\
\text { integration, knowledge sharing, achievement } \\
\text { transformation and risk sharing }\end{array}$ & Gao Hang [39] (2015) \\
\hline $\begin{array}{c}\text { Research performance } \\
\text { evaluation model of public } \\
\text { research institutes }\end{array}$ & $\begin{array}{c}\text { RELEV Model } \\
\text { II }\end{array}$ & $\begin{array}{c}\text { Input: government funds, research and } \\
\text { technical personnel, labor costs } \\
\text { Outputs: income, graduate staff, number of } \\
\text { courses, international publications, national } \\
\text { publications, international conferences, } \\
\text { national conferences }\end{array}$ & Coccia M[40] (2005) \\
\hline $\begin{array}{c}\text { Performance evaluation } \\
\text { index system of industrial } \\
\text { technology institutes }\end{array}$ & $\begin{array}{c}\text { Bibliometric } \\
\text { method } \\
\text { scientific and technological output, } \\
\text { innovation benefit, social service, operation } \\
\text { mode, assessment mechanism, innovation } \\
\text { field, innovation income, management } \\
\text { mechanism, financial index }\end{array}$ & Jiang Hailing et al. [41] \\
(2016)
\end{tabular}

\section{CONCLUSion}

In the context of national implementation of innovationdriven strategy, in order to realize "technology + capital + education + industry" mode of "four-in one", to realize the innovative construction from research and development base and activities to system and mechanism innovation, technology research and development and achievements, incubating imported business, gathering and cultivating talents so as to realize social benefit, government, enterprises, research institutes and other innovative main bodies of conduct continuous resources integration and cooperate to establish new types of scientific research institutions. New types of scientific research institutions play a bridge role between science and technology and economy in the whole value chain of scientific and technological innovation, and gradually become a new engine of regional industrial transformation and upgrading.

The new types of scientific research institutions are characterized by diversified investment bodies, marketoriented resource allocation, enterprise-oriented management mechanism, demand-oriented R\&D direction, and internationalized talent team. With knowledge exploration and scientific and technological innovation as the main activities, they are committed to the industrialization of scientific and technological achievements and can lead the construction of regional innovation system. Their construction is mainly led by the government, universities, scientific research institutes, enterprises, social organizations or individuals and the universities and governments coconstruction type accounts for a relative large proportion. The existing research on operating mechanism mainly focuses on management mechanism, collaborative innovation mechanism, personnel incentive mechanism, achievement transformation mechanism and other aspects, so the internal mechanism of resource investment, risk control and benefit distribution is worth continuous exploration. The research on operation effect can be carried out by constructing a complete index system for empirical analysis, so as to accurately analyze its operation effect and improve its service level.

\section{REFERENCES}

[1] Chen Xue, Zhang Zhitong. The Innovation and Thinking of Innovative and Research and Development Institutions Promoting "Mass Innovation \& Entrepreneurship" [J]. Science and Technology Management Research, 2016, 36(22): 87-91.(in Chinese)

[2] Wu Wei, Chen Luoku. Research on Mechanism of Formation and Function of New Type R\&D Institutions under Different Information Conditions - from the Perspective of Innovation Driven Development [J]. Science and Technology Management Research, 2008, 38(11): 87-94. (in Chinese)

[3] Li Min. Enlightenment on New Research and Development Institutions by Haier Open Partnership Ecosystem [J]. Science and Technology Management Research, 2017, 37(17): 124-130. (in Chinese)

[4] Chen Baoming, Liu Guangwu, Ding Minglei. Research on the Development Status and Policy Recommendations of Chinese Newtype R\&D Organization [J]. Forum on Science and Technology in China, 2013(3): 27-31. (in Chinese)

[5] Zeng Guoping, Lin Fei. Towards Interpreneurial Research Institutes - A Trial Study on the New Type of Research Instituts in Shenzhen [J]. China Soft Science, 2013(11): 49-57. (in Chinese)

[6] Chen Hongxi, Jiang Chun, Luo Lihua, et al. Performance Evaluation System Design for Technology Transformation and Diffusion of New Research and Development Institutes [J]. Journal of Intelligence, 2018, 37(8): 113, 162-171. (in Chinese)

[7] Mu Miao. Advantages Analysis of New R\&D Institutions Promoting the Transformation of Scientific and Technological Achievements [J]. Management \& Technology of SME (mid-month), 2016(2): 153-154. (in Chinese)

[8] Duan Jingjing. Research on collaborative innovation performance improvement of industry-university-research institutes - a theoretical analysis framework [J]. Inner Mongolia Social Sciences (Chinese version), 2014, 35(2): 119-123. (in Chinese) 
[9] Wu Wei, Yin Lu. Pasteur Quadrant Orientation Model and Function Location of New R\&D Institution [J]. Technology Economics, 2016, 35(8): 38-44. (in Chinese)

[10] Gao Ranhui, Zhang Weiwei. Research on the Development Status of New R\&D Institutions in China [J]. ValueEngineering, 2015, 34(33): 45-47. (in Chinese)

[11] Tao Xiaoli, Wang Haiyun, Huang Lu, et al. Research on the Modes of Market-Oriented Allocation of Top Innovative Elements [J]. Forum on Science and Technology in China, 2017(5): 5-11. (in Chinese)

[12] Ma Dexiu. Promoting the Development of New R\&D Organizations by Deepening the Reform of Science and Technology System [N]. China Economic Herald, 2014-01-25 (B01). (in Chinese)

[13] Ji Songlei, Zhu Yuezhao, Wang Xiao. Research on Innovation of Cooperation Mode of Industry, University and Research Institutue [J]. Journal of Nanjing Technology University (social science edition), 2011, 10(1): 86-89. (in Chinese)

[14] Tan Li, Chen Yushan. Research and Proposal on the Construction Mode of New Scientific Institutions in Guangdong [J]. Science and Technology Management Research, 2015, 35(20): 45-49. (in Chinese)

[15] Zhao Jiandong, Dai Qingyun. Study on Construction of New Innovation System Based on Data Analysis of New Research and Development Institutions [J]. Science and Technology Management Research, 2017, 37(20): 82-87. (in Chinese)

[16] Zhou Ende, Liu Guoxin. Empirical Research on Factors Influencing Innovation performance of New R\&D Institutions in China - a Case Study of Guangdong Province [J]. Science \& Technology Progress and Policy, 2018, 35(9): 42-47. (in Chinese)

[17] Liu Hui, Yang Zhongtai. Operation mode and function orientation of local industrial technology research institute - based on practice exploration of Shaanxi Province [J]. Economic Research Guide, 2017(14): 166-169. (in Chinese)

[18] Micheal Fritsch \& Christian Schwirten (1999) Enterprise-University Co-operation and the Role of Public Research Institutions in Regional Innovation Systems, Industry and Innovation, 6: 1, 69-83.

[19] Zhang Yulei, Li Runyi, Liu Yixin, et al. Analysis and Research on the Current Situation of New R\&D Institutions in Guangdong Province [J]. Science and Technology Management Research, 2018, 38(13): 124-132. (in Chinese)

[20] Zhou Li. Study on the Operating Mechanism of "Four Dissimilarities" of New Research and Development Institutions in Universities [J]. Technoeconomics \& Management Research, 2016 (7): 39-43. (in Chinese)

[21] Etzkowitz H. Research groups as 'quasi-firms': the invention of the entrepreneurial university [J]. Research Policy, 2003, 32(1): 109-121.

[22] Yang Minghai, Jing Yang, Wang Yanjie, et al. Exploration and Research of the Industrial Technology Institute - Based on the Industrial Technology Research Institute of Tianjin University [J]. Science and Technology Management Research, 2013, 33(24): 92-94, 103. (in Chinese)

[23] Lin Zhijian. Innovation Thinking about the Operation Mode of Government-sponsored Industrial Technology Research Institute [J]. Science and Technology Management Research, 2013, 33(21): 37-40. (in Chinese)

[24] Ding Minglei, Chen Baoming. Research on the New Initiatives of the American Federal Financial Support to the New R\&D Institutions [J]. Science and Technology Management Research, 2015, 33(2): 109112. (in Chinese)

[25] Huang Yuxing, Jin Qinxian. Development mode of industrial technology research institute [J]. High-Technology \& Industrialization, 2011(8): 20-22. (in Chinese)

[26] Xia Taishou, Zhang Yufu, GaoRanhui, et al. Research on Collaborative innovation mode and mechanism of China's New R\&D Institutions [J]. Science \& Technology Progress and Policy, 2014, 31(14): 13-18. (in Chinese)

[27] Zuo Chaosheng. Emerge at the right moment - Huang Ningsheng, director of guangdong provincial department of science and technology, talks about new R\&D institutions [J]. Guangdong science and technology, 2014, 23(23): 16-20. (in Chinese)
[28] Zhou Huadong. The Development and Evolution of Operating Mechanism of Industrial Technology Institute [J]. Forum on Science and Technology in China, 2015(11): 29-33. (in Chinese)

[29] Li Peizhe, Jian Lirong, Pei Shanshan, et al. The Research on Organization Mode and Operation Mechanism of Enterprise Leading Industrial Technology Research Institute [J]. Science \& Technology Progress and Policy, 2014, 31(12): 65-69. (in Chinese)

[30] Zhang Xichun, Jiang Hai, Zhang Wen, et al. Comparison and research of new R\&D institutions at home and abroad [J]. Science and Technology Management Research, 2017, 37(19): 103-109. (in Chinese)

[31] Zou Runrong. Research on collaborative innovation mechanism of new scientific research institutions [J]. GuangDong Science \& Technology, 2013, 22(16): 4-5. (in Chinese)

[32] Yuan Chuansi. Research on the Main Body of the New R\&D Institute in the Industrial Technology Alliance [J]. Science and Technology Management Research, 2016, 36(9): 112-115, 125. (in Chinese)

[33] Zheng Shujun. Ways to create characteristic innovation by combining technology and talents - analysis on the construction of shenzhen institute of advanced technology, Chinese academy of sciences [J] GuangDong Science \& Technology, 2012, 21(10): 34-36. (in Chinese)

[34] Jiang Jian, Li Xin, Zhang Jiali. Development status, mechanism innovation and Suggestions of new R\&D institutions in Dongguan [J]. Operating and Management, 2017(2): 106-109.(in Chinese)

[35] Feng Guanping, Wang Debao. The Function of Technology Innovation Platform for the Development of Science, Technology and Economy in Shenzhen [J]. China Soft Science, 2005(7): 15-19, 24. (in Chinese)

[36] Wang Shouwen, Xu Wanqiang, Yan Peng. Research on the Evaluation Model of Research Institute of Industrial Technology Performance Based on AHP [J]. Science \& Technology Progress and Policy, 2014, 31(17): 120-125. (in Chinese)

[37] Vinkler P. General performance indexes calculated for research institutes of the Hungarian Academy of Sciences based on scientometric indicators [J]. Scientometrics, 1998, 41(1-2): 185-200.

[38] Wang Shouwen, Yan Peng. Study on evaluation system of Operation Performance of Secondary City Industrial Technology Research Institute [J]. Science \& Technology Progress and Policy, 2015, 32(18) 114-120. (in Chinese)

[39] Gao Hang. Study on the Evaluation System of Synergy Innovation Platform of Industrial Technology Research Institute [J]. Studies inScience of Science, 2015, 33(2): 313-320. (in Chinese)

[40] Coccia M . A scientometric model for the assessment of scientific research performance within public institutes[J]. Scientometrics, 2005 , 65(3): 307-321.

[41] Jiang Hailing, Wang Lei, Wang Jining, et al. An Internationa Comparative Study of Performance Evaluation on Industrial Technology Research Institutes [J]. Journal of Nanjing Tech University (Social Science Edition), 2016, 15(1): 109-114. (in Chinese)

[42] Yang Bowen, Tu Ping. Research on Evaluation Index System of New $\mathrm{R} \& \mathrm{D}$ Institutions in Beijing [J]. Science Research Management, 2018 39(S1): 81-86. (in Chinese) 